\title{
IL-10 and ARG-1 Concentrations in Bone Marrow and Peripheral Blood of Metastatic Neuroblastoma Patients Do Not Associate with Clinical Outcome
}

\author{
Fabio Morandi, ${ }^{1}$ Michela Croce, ${ }^{2}$ Giuliana Cangemi, ${ }^{3}$ Sebastiano Barco, ${ }^{3}$ \\ Valentina Rigo, ${ }^{2}$ Barbara Carlini, ${ }^{1}$ Loredana Amoroso, ${ }^{4}$ Vito Pistoia, \\ Silvano Ferrini, ${ }^{2}$ and Maria Valeria Corrias ${ }^{1}$ \\ ${ }^{1}$ Laboratorio di Oncologia IRCCS Istituto Giannina Gaslini, 16148 Genova, Italy \\ ${ }^{2}$ Laboratorio di Bioterapia, IRCCS AOU San Martino-Istituto Nazionale per la Ricerca sul Cancro, 16132 Genova, Italy \\ ${ }^{3}$ Laboratorio di Patologica Clinica IRCCS Istituto Giannina Gaslini, 16148 Genova, Italy \\ ${ }^{4}$ U.O. Oncologia IRCCS Istituto Giannina Gaslini, 16148 Genova, Italy
}

Correspondence should be addressed to Maria Valeria Corrias; mariavaleriacorrias@ospedale-gaslini.ge.it

Received 1 August 2014; Accepted 25 September 2014

Academic Editor: Marco Antonio Velasco-Velázquez

Copyright (C) 2015 Fabio Morandi et al. This is an open access article distributed under the Creative Commons Attribution License, which permits unrestricted use, distribution, and reproduction in any medium, provided the original work is properly cited.

The expression of the immunosuppressive molecules $I L-10$ and arginase 1 (ARG-1), and of FOXP3 and CD163, as markers of regulatory $\mathrm{T}$ cells (Treg) and macrophages, respectively, was evaluated in bone marrow (BM) and peripheral blood (PB) samples collected at diagnosis from patients with metastatic neuroblastoma (NB). IL-10 and ARG-1 plasma concentrations were measured and the association of each parameter with patients' outcome was tested. The percentages of immunosuppressive Treg and type-1 regulatory (Tr1) cells were also determined. In both BM and PB samples, $I L-10$ mRNA expression was higher in metastatic NB patients than in controls. IL-10 plasma concentration was higher in patients with NB regardless of stage. Neither IL-10 expression nor IL-10 plasma concentration significantly associated with patient survival. In PB samples from metastatic NB patients, ARG-1 and CD163 expression was higher than in controls but their expression did not associate with survival. Moreover, ARG-1 plasma concentration was lower than in controls, and no association with patient outcome was found. Finally, in metastatic NB patients, the percentage of circulating Treg was higher than in controls, whereas that of Tr1 cells was lower. In conclusion, although IL-10 concentration and Treg percentage were increased, their contribution to the natural history of metastatic NB appears uncertain.

\section{Introduction}

It is generally assumed that the efficacy of anticancer immunotherapy is hampered by immune suppressive and tolerogenic mechanisms, including soluble factors, produced by both neoplastic and other tumor-instructed immune suppressive cells [1].

Neuroblastoma (NB) is a pediatric neuroectodermal solid tumor with a heterogeneous clinical behavior [2]. Children presenting with metastatic disease at diagnosis, that is, stage 4 according to the International Neuroblastoma Staging System (INSS) [3] or stage M according to the International Neuroblastoma Risk Group Staging System (INRG-SS) [4], aged more than 18 months, have poor survival rate despite intensive multimodal therapy. In these patients, immunotherapy with anti-disialoganglioside GD2 (GD2) antibody, with or without IL-2 or granulocyte macrophage-colony stimulating factor (GM-CSF), is administered in a minimal residual disease condition after myeloablative therapy, in ongoing high-risk protocols of the Children Oncology Group (COG) [5] and the International Society of Pediatric Oncology-European Neuroblastoma (SIOPEN) [6]. It is of note that, in spite of low/absent Human Leucocyte Antigen (HLA) class I expression by NB cells [7], resting NK cells have limited efficacy against neuroblasts, because the latter cells express an inhibitory ligand [8] and may release immunosuppressive soluble factors [9-13]. Nonetheless, the combination of 
anti-GD2 mAb with IL-2 or GM-CSF can activate NK-cell or granulocyte mediated antibody dependent cell-mediated cytotoxicity (ADCC) against NB cells and lead to improved survival [14].

In human NB, information on the presence and activity of specific subsets of immune suppressive cells and soluble factors is limited [15]. A gene expression study performed on primary tumors [16] suggested a role for arginase (ARG)$1^{+}$myeloid-derived suppressor cells in the prognosis of metastatic NB patients. Recently, the same authors [17] demonstrated that tumors from high-risk NB patients present greater infiltration with $\mathrm{CD}_{163}{ }^{+} \mathrm{M} 2$-type tumor associated macrophages (TAM). In addition, Song et al. showed that NKT cell-mediated killing of TAMs associated with a better outcome [18].

Immune suppressive $\mathrm{CD} 4{ }^{+} \mathrm{CD} 25^{+} \mathrm{FOXP}^{+}$regulatory $\mathrm{T}$ cells (Treg) are increased in several types of tumors, where they may play a relevant tolerogenic role [19]. However, no increase in their number was found in a small cohort of localized and metastatic NB patients [20].

A potential immunosuppressive role of $\mathrm{T}$ regulatory type 1 (Tr1) cells has never been investigated in NB patients. Tr1 cells have been firstly identified in mice as $\mathrm{CD}^{+} \mathrm{T}$ cells secreting high amounts of IL-10 [21]. Subsequently, Tr1 cells have also been characterized in humans [22-24] and are now identified as $\mathrm{CD} 4^{+} \mathrm{CD} 45 \mathrm{R} 0^{+} \mathrm{CD} 49 \mathrm{~b}^{+} \mathrm{LAG}-3^{+} \mathrm{T}$ cells [25].

The immunosuppressive cytokine IL-10 is produced by both Treg and Trl cells and by cells of the innate immunity, such as NK cells and macrophages [26]. Gowda et al. have shown that, in patients with localized NB, plasma IL-10 concentration was higher than in patients with metastatic disease and suggested that high IL-10 levels may reflect the activation of an effective innate immunity [20].

Our working hypothesis is that, in patients with metastatic NB, bone marrow- (BM-) infiltrating and circulating tumor cells could contribute to the instruction of different immune suppressive mechanisms in the periphery. We thus evaluated the mRNA expression of $I L-10, F O X P 3$, as marker of Treg, and $A R G-1$ and CD163, as markers of myeloid suppressor cells/macrophages in both BM and peripheral blood (PB) samples collected at diagnosis from metastatic NB patients. We also measured IL-10 and ARG-1 plasma levels and these markers of immune suppressive mechanisms were tested for association with event-free and overall survival (EFS and OS, resp.). Finally, we determined the percentage of Treg and Trl cells in PB samples from metastatic NB patients and age-matched controls.

\section{Materials and Methods}

2.1. Patients. Forty-one consecutive patients diagnosed in Italy with stage $4 \mathrm{NB}$ between November 2001 and December 2006, aged $>18$ months at onset, were included in the molecular analysis if both BM and PB samples collected at diagnosis were available. Disease staging [3] was made at the referring oncology center and centrally reviewed at the Gaslini Institute. The median age at diagnosis was 2.9 years (range: 1.5-9.7) and the median follow-up was 39.2 months (range: 10.4-97.4). Thirty \% of the patients presented MYCN amplification. As controls for molecular analysis, 20 BM samples and 20 PB samples from 40 healthy donors were used after informed consent was given.

ELISA was performed on plasma samples collected at diagnosis from a total of $102 \mathrm{NB}$ patients (50 stage 4 and 52 non-stage 4) admitted to the Gaslini Institute between January 1994 and December 2010. As controls, 55 plasma samples collected between January 2010 and December 2012 from children admitted to the Gaslini Institute for accidental injuries were used. The median age at diagnosis of the stage 4 patients was 3.4 years (range: 1.6-9.6) and the median followup was 20.3 months (range: 6.8-138.5). Twenty-six \% of stage 4 patients and $29.1 \%$ of non-stage 4 patients presented $M Y C N$ amplification.

IL-10 determination was performed on all plasma samples available, whereas ARG-1 was tested on a fraction of them, since not enough plasma was available to perform both assays; namely, 57 plasma samples from NB patients (49 stage 4 and 8 non-stage 4 ) and 30 from healthy age-matched controls were analyzed. All samples were stored at $-80^{\circ} \mathrm{C}$ until use.

Follow-up data at January 2014 were retrieved from the Italian Neuroblastoma Registry (INBR) [27]. The studies were approved by the institutions' ethical committees and all analyses were performed according to the Helsinki declaration.

2.2. RNA Extraction and RT-qPCR Analysis. Total RNA was extracted from $\mathrm{PB}$ or BM samples as described in [28]. One hundred ng of total RNA was reverse transcribed and then amplified for each molecular marker in duplicate by qPCR, using the following assays from Life Technology (Life Technologies Europe BV, Monza, Italy): IL-10: Hs00961622_m1, FOXP3: Hs00203958_m1, CD163: Hs00174705_m1, ARG-1: Hs00968979_ml, and primers and probe for $\beta 2$-microglobulin $(\beta 2 M)$ [29]. The level of expression of each marker was normalized to the expression of $\beta 2 M$, according to the delta Ct method [30], and results were reported as $2^{-\Delta \mathrm{Ct}}$.

To exclude DNA contamination, samples in the absence of reverse transcriptase were analyzed in each qPCR assay, and water was included as negative control.

2.3. ELISA. ARG-1 and IL-10 concentrations were measured using Arginase I Human ELISA kit (Hycult Biotech, Milan, Italy) and human high sensitivity IL-10 ELISA Kit (Diaclone Gen-Probe, Besançon Cedex, France), respectively, following manufacturers' protocols.

2.4. Flow Cytometry. The percentage of Treg and Tr1 cells was evaluated by flow cytometry on whole PB samples. Treg were identified using Human Regulatory T Cell Cocktail (BD Biosciences, Milan, Italy), containing anti-CD4 FITC, anti-CD25 PE-Cy7, and anti-CD127Alexa Fluor 647 antibodies, following manufacturer's protocol. Tr1 were evaluated using anti-CD4 PE-Cy7 (eBiosciences, San Diego, CA), antiCD45R0 APC (eBiosciences), anti-CD49b PE (R\&D Systems, Space, Milan, Italy), and anti-LAG-3 FITC (R\&D Systems) antibodies. Samples were subjected to erythrocytes lysis using 


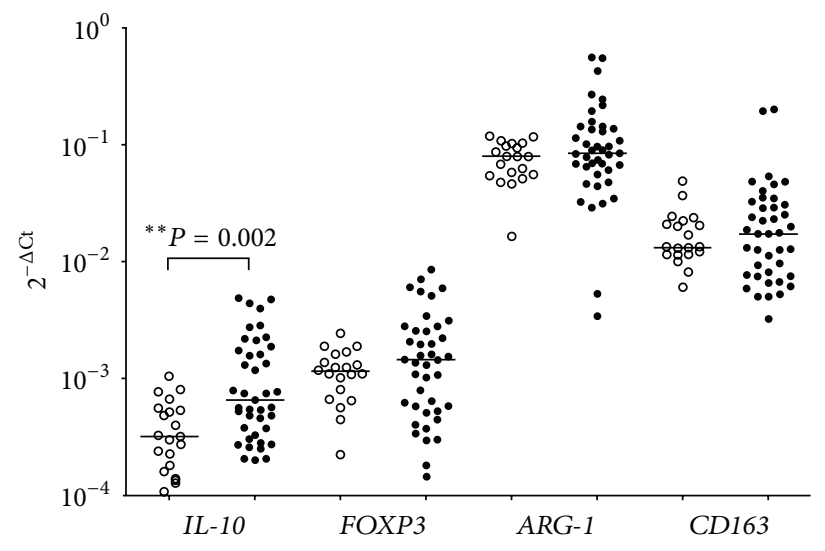

(a)

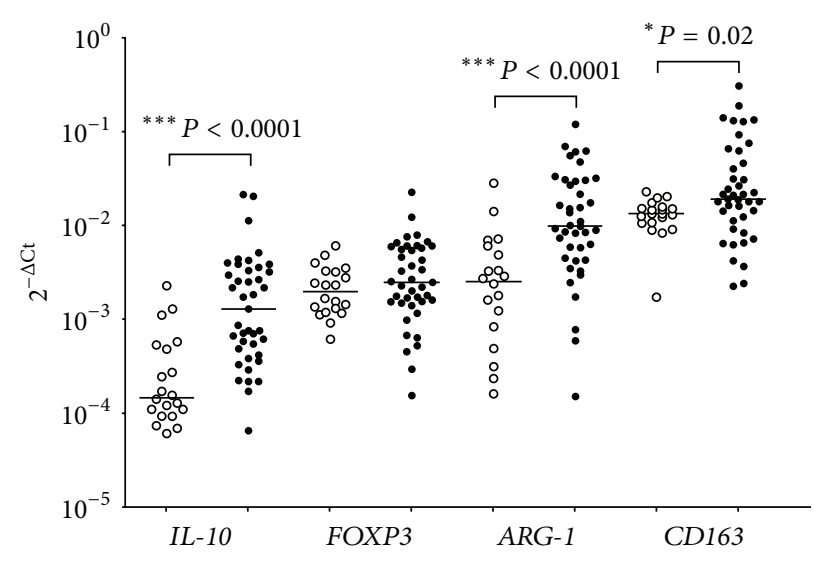

(b)

FIGURE 1: Expression of IL-10, FOXP3, ARG-1, and CD163 mRNA in BM (a) and PB (b) samples from 41 high-risk NB patients (black circles) and 20 healthy controls (empty circles). Data are expressed as $2^{-\Delta \mathrm{Ct}}$ values. Horizontal bars indicated medians. $P$ values are indicated where differences are significant.

BD FACS lysis (BD Biosciences) and washed. Cells were run on Gallios cytometer (Beckman Coulter, Cassina De' Pecchi, MI, Italy) acquiring at least $10^{4}$ events. Data were analyzed using Kaluza software (Beckman Coulter). Treg were identified as $\mathrm{CD} 4^{+} \mathrm{CD} 25^{\text {high }} \mathrm{CD} 127^{\text {low }}$ cells, whereas $\mathrm{Tr} 1$ were identified as $\mathrm{CD} 4^{+} \mathrm{CD} 45 \mathrm{R} 0^{+} \mathrm{CD} 49 \mathrm{~b}^{+} \mathrm{LAG}-3^{+}$cells [25].

2.5. Statistical Analysis. Gaussian distribution of data was analyzed using Kolmogorov-Smirnov test. $t$-test or MannWhitney test was used to compare values depending on Gaussian distribution, while the Spearman $\rho$ coefficient was used to assess correlation between variables. EFS and OS analyses were performed according to the Kaplan-Meier method and compared by the log-rank test. A $P$ value $<0.05$ was considered statistically significant. Analyses were made using the Prism software (GraphPad Software Inc., La Jolla, CA).

\section{Results}

3.1. Expression of IL-10, FOXP3, ARG-1, and CD163 in BM and $P B$ Samples and Association with EFS and OS. Expression of IL-10, FOXP3, ARG-1, and CD163 mRNAs was analyzed by RT-qPCR in BM and PB samples collected at diagnosis from 41 children with metastatic NB and from 20 healthy donors. As shown in Figure 1(a), the expression of $I L-10$ mRNA in BM samples was significantly higher in NB patients $\left(2^{-\Delta \mathrm{Ct}}: 1.28 \times\right.$ $\left.10^{-3} \pm 1.32 \times 10^{-3}\right)$ than in controls $\left(2^{-\Delta \mathrm{Ct}}: 0.41 \times 10^{-3} \pm 0.26 \times\right.$ $\left.10^{-3} ; P=0.002\right)$, whereas the expression of FOXP3, ARG-1, and CD163 mRNAs was similar between the two groups.

In $\mathrm{PB}$ samples, metastatic $\mathrm{NB}$ patients showed higher expression of $I L-10\left(2^{-\Delta \mathrm{Ct}}: 2.89 \times 10^{-3} \pm 4.66 \times 10^{-3}\right.$ versus $\left.0.41 \times 10^{-3} \pm 0.56 \times 10^{-3} ; P<0.0001\right)$, ARG-1 $\left(2^{-\Delta \mathrm{Ct}}:\right.$ $20.21 \times 10^{-3} \pm 24.32 \times 10^{-3}$ versus $4.54 \times 10^{-3} \pm 6.54 \times 10^{-3}$; $P<0.0001)$, and CD163 (2 ${ }^{-\Delta \mathrm{Ct}}: 45.2 \times 10^{-3} \pm 62.2 \times 10^{-3}$ versus $\left.13.5 \times 10^{-3} \pm 4.7 \times 10^{-3} ; P=0.02\right)$ mRNAs than healthy donors (Figure 1(b)).

However, no association with EFS or OS was found for any of the four markers analyzed, either in BM (Supplemental Figures 1(a) and 1(b), resp., available online at http://dx.doi.org/10.1155/2015/718975) or in PB samples (Supplemental Figures 2(a) and 2(b), resp.).

3.2. Correlations between IL-10, FOXP3, ARG-1, and CD163 $m R N A$ Expression in BM and PB Samples. We next analyzed potential correlations in the mRNA expression levels of the four markers in both BM and PB samples. In BM samples, $I L-10$ expression positively correlated with FOXP3 $(r=0.43$; $P=0.0046$, Figure 2(a)) and CD163 expression $(r=0.45$; $P=0.0028$, Figure 2(b)). In PB samples, CD163 correlated with ARG-1 ( $r=0.51 ; P=0.0005$, Figure 2(c)), whereas $I L-10$ showed an inverse correlation with FOXP3 $(r=-0.67$; $P<0.0001$, Figure 2(d)). These data suggested that IL-10 production in BM may be ascribed to both $\mathrm{CD}_{163}{ }^{+}$and Treg cells, whereas in PB IL-10 was unlikely produced by $\mathrm{FOXP}^{+}$cells. Conversely, in $\mathrm{PB}, \mathrm{CD} 163^{+}$myeloid cells may be responsible for ARG-1 production.

3.3. NB Patients Display an Increased Plasma Concentration of $I L-10$ Irrespective of Disease Stage. Given the high expression of $I L-10$ mRNA in metastatic NB patients, we then measured IL-10 plasma concentration. As shown in Figure 3(a), IL10 concentration was significantly higher in metastatic NB patients $(8.68 \pm 4.45 \mathrm{pg} / \mathrm{mL})$ than in age-matched controls $(0.41 \pm 0.19 \mathrm{pg} / \mathrm{mL}, P<0.0001)$. However, when we compared IL-10 plasma levels in metastatic and localized NB patients, no significant difference was found (Figure 3(b), stage 4: $12.18 \pm 7.44 \mathrm{pg} / \mathrm{mL}$; non-stage $4: 6.35 \pm 3.5 \mathrm{pg} / \mathrm{mL}$ ). In addition, as observed for $I L-10$ mRNA expression, IL-10 plasma levels in metastatic NB patients did not associate with either EFS (Figure 3(c)) or OS (Figure 3(d)). 


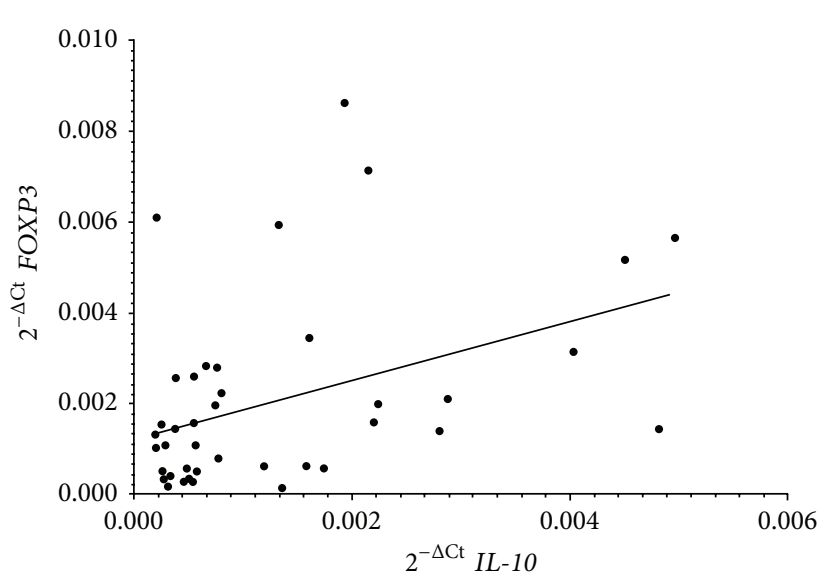

(a)

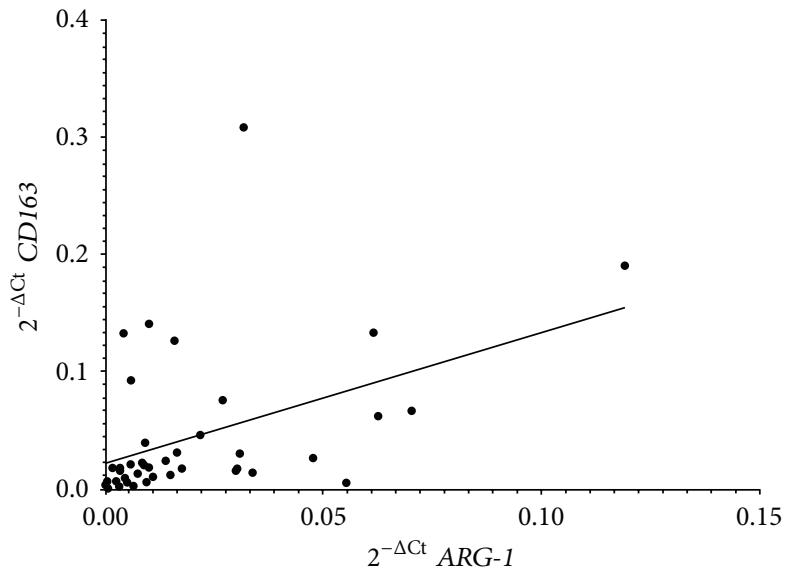

(c)

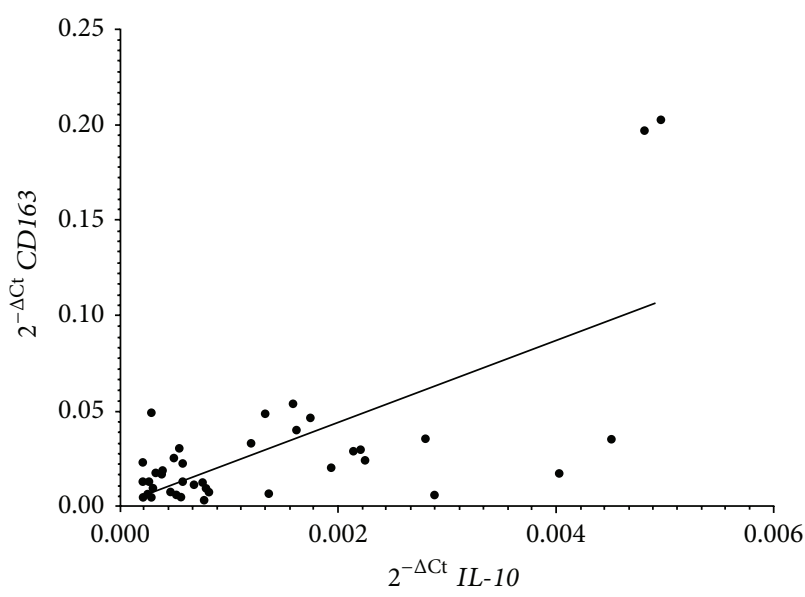

(b)

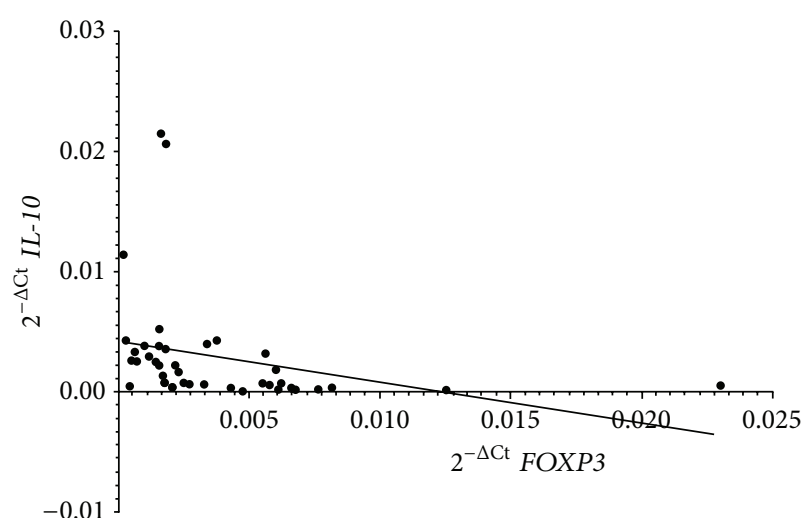

(d)

FIgURE 2: Correlations between $I L-10$ and FOXP3 (a) and $I L-10$ and CD163 mRNA (b), in BM samples, and ARG-1 and CD163 (c) and FOXP3 and $I L-10(\mathrm{~d})$ mRNA in PB samples from 41 high-risk NB patients. Data are expressed as $2^{-\Delta \mathrm{Ct}}$ values.

3.4. NB Patients Display Lower Plasma Concentration of ARG-1 than Healthy Subjects. We next analyzed the plasma concentration of soluble ARG-1 in PB samples. In contrast with the mRNA expression, ARG-1 concentration was significantly lower in NB patients $(19.52 \pm 4.58 \mathrm{pg} / \mathrm{mL})$ than in age-matched controls $(44.89 \pm 4.17 \mathrm{pg} / \mathrm{mL}, P<0.0001$, Figure 4(a)). However, ARG-1 concentration was significantly higher in stage $4(22.49 \pm 5.41 \mathrm{pg} / \mathrm{mL})$ than in nonstage $4(8.2 \pm 5.1 \mathrm{pg} / \mathrm{mL}, P=0.01) \mathrm{NB}$ patients (Figure $4(\mathrm{~b})$ ), suggesting that ARG-1 release may be related to a more advanced disease stage. However, no significant correlation was found between ARG-1 plasma levels in metastatic NB patients and their EFS (Figure 4(c)) or OS (Figure 4(d)).

3.5. Treg but Not Tr1 Cells Are Expanded in PB from NB Patients. Since we detected increased IL-10 plasma levels in NB patients, we asked whether two regulatory $\mathrm{T}$ cell populations able to secrete IL-10, namely, $\mathrm{CD} 4^{+} \mathrm{CD} 25^{\text {high }} \mathrm{CD} 127^{\text {low }}$ Treg and $\mathrm{CD} 4{ }^{+} \mathrm{CD} 45 \mathrm{R} 0^{+} \mathrm{CD} 49 \mathrm{~b}^{+} \mathrm{LAG}-3^{+} \mathrm{Tr} 1$ cells, were also increased. As shown in Figure 5, the percentage of Treg was significantly higher in metastatic NB patients (\% of cells:
$0.91 \pm 0.39)$ than in age-matched controls ( $\%$ of cells: $0.32 \pm$ $0.06, P=0.02)$, whereas the percentage of $\operatorname{Tr} 1$ cells was lower in NB patients (\% of cells: $1.1 \pm 0.19)$ than in controls $(2.32 \pm 0.4, P=0.01)$.

\section{Discussion}

To the best of our knowledge, this is the first report where both $\mathrm{BM}$ and $\mathrm{PB}$ samples from metastatic NB patients were analyzed to evaluate the prognostic role of immune suppressive soluble factors and cell subsets. In addition, this is the first report on Tr-1 cells in NB.

Our study clearly shows that $I L-10$ mRNA expression levels were significantly increased in both $\mathrm{PB}$ and $\mathrm{BM}$ samples and plasma IL-10 concentration was also elevated. However, no significant association with clinical outcome was found. In addition, similar IL-10 plasma levels were found in children with metastatic and localized NB, whose prognosis is completely different [4], confirming that increase in IL10 concentration is unrelated to stage and prognosis. These findings are different in part from those reported by Gowda 


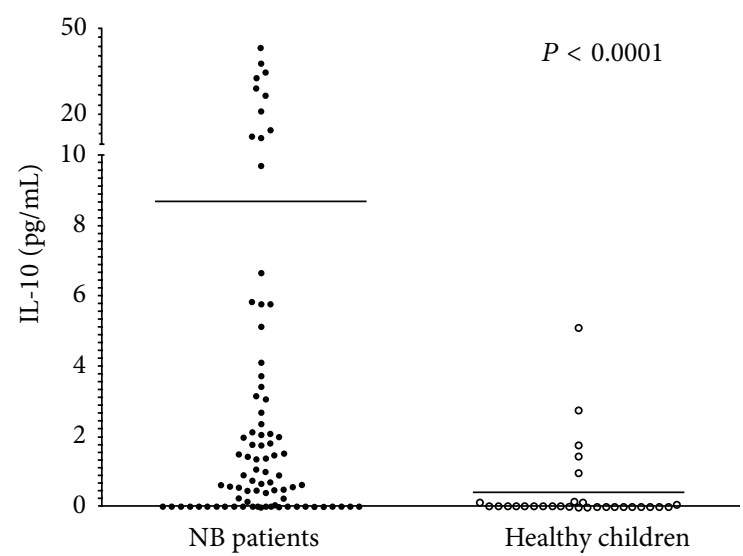

(a)

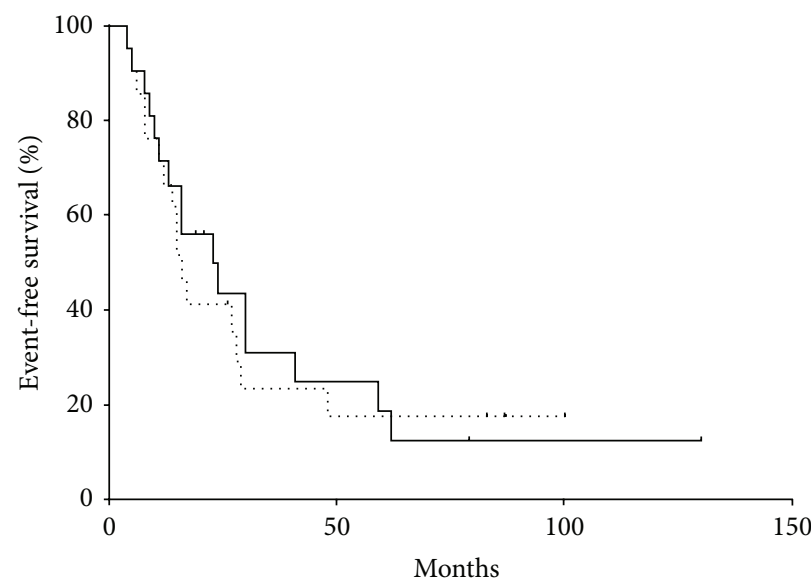

IL-10 plasma levels
- Below median
$\ldots . .$.

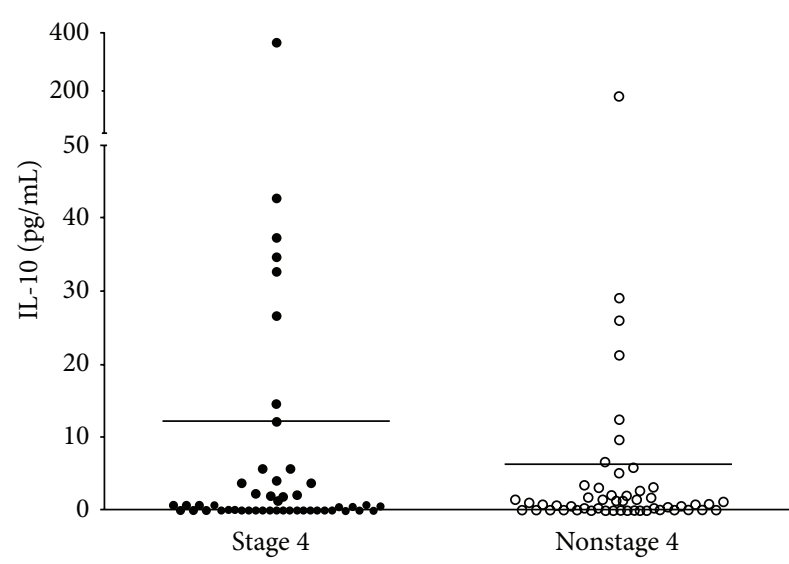

(b)

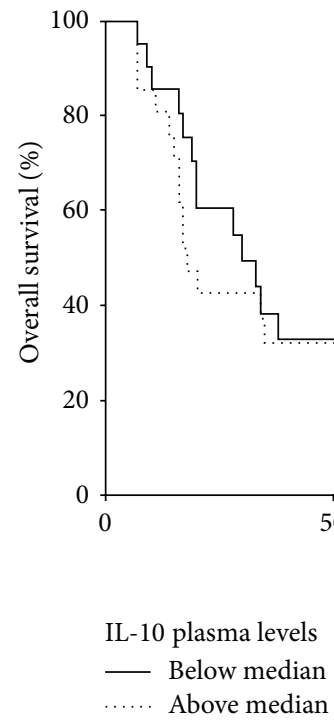

(c)

(d)

FIGURE 3: IL-10 plasma concentration in $102 \mathrm{NB}$ patients and 55 healthy children $(\mathrm{a}, \mathrm{b})$ and association between IL-10 plasma levels of stage 4 patients with EFS and OS (c, d). In (a), all NB patients and controls are shown. In (b), NB patients are stratified in stage $4\left(n^{\circ}=50\right)$ and non-stage $4\left(n^{\circ}=52\right)$. Results are expressed as pg/mL. Horizontal bars indicate means. $P$ values are indicated where differences are significant. Kaplan-Meyer plot of EFS (c) and OS (d) obtained by stratifying the 50 stage 4 NB patients according to IL-10 plasma levels above (dotted line) or below (continuous line) median value. $Y$-axes represent $\%$ of event-free or alive patients, respectively. $X$-axes represent time of survival (months).

et al., showing higher IL-10 plasma concentration in the low-risk group of a small cohort of NB patients [20]. This discrepancy may be related to the study of larger cohorts of patients, belonging to stage 4 and non-stage 4 , in the present report than in the previous one. Moreover, in our study, only patients $>18$ months at diagnosis were included, thus excluding the effect of age.

Our study also shows that the significant increase of $A R G$ 1 mRNA levels in PB did not correspond to elevated ARG1 plasma concentration. This finding may be related to the fact that ARG-1 plasma levels depend on the amount released by MDSC or by granulocytes, following their degranulation. However, neither $A R G-1$ expression nor ARG-1 plasma concentration significantly associated with survival of metastatic NB patients. Thus, our results do not support a relevant role of IL-10 and ARG-1 in the natural history of metastatic NB.
The finding that $I L-10$ expression levels in BM significantly correlated with both FOXP3 and CD163 expression suggested that IL-10 can be produced not only by the $\mathrm{CD} 4^{+} \mathrm{CD} 25^{\text {high }} \mathrm{CD} 127^{\text {low }}$ Treg cells, as already demonstrated [31], but also by $\mathrm{CD} 163^{+}$macrophages. These data are in accordance with previous reports showing a significant correlation between $\mathrm{CD}_{163^{+}}$TAM and IL-10 release [32-34]. Surprisingly, in PB samples from metastatic NB patients, $I L-$ 10 expression inversely correlated with FOXP3 expression and no correlation was found with CD163 expression, making it unlikely that Treg or macrophages could be responsible for IL-10 production in PB.

In our study, the increased percentage of Treg found in metastatic NB patients appeared to be compensated by a decrease in the other regulatory $\mathrm{T}$ cell subsets able to secrete IL-10 [35], the Trl cells. The increased percentage of Treg cells 


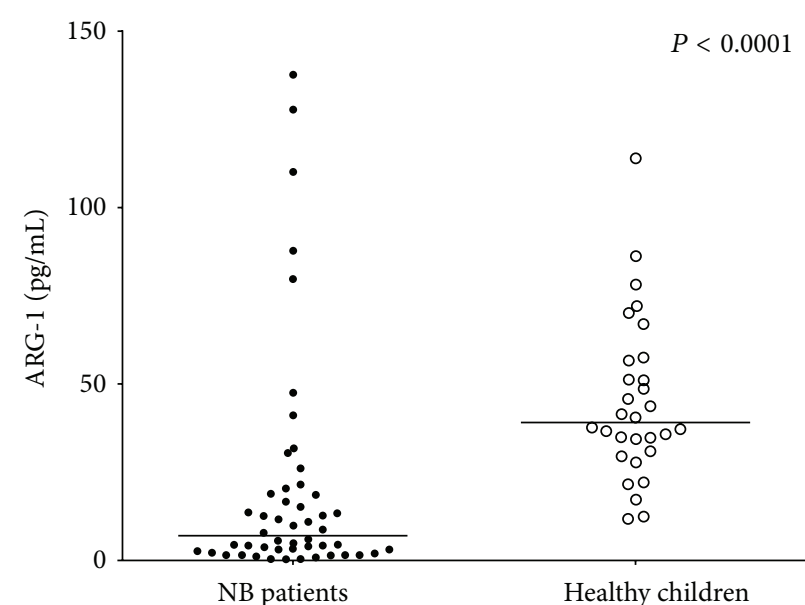

(a)

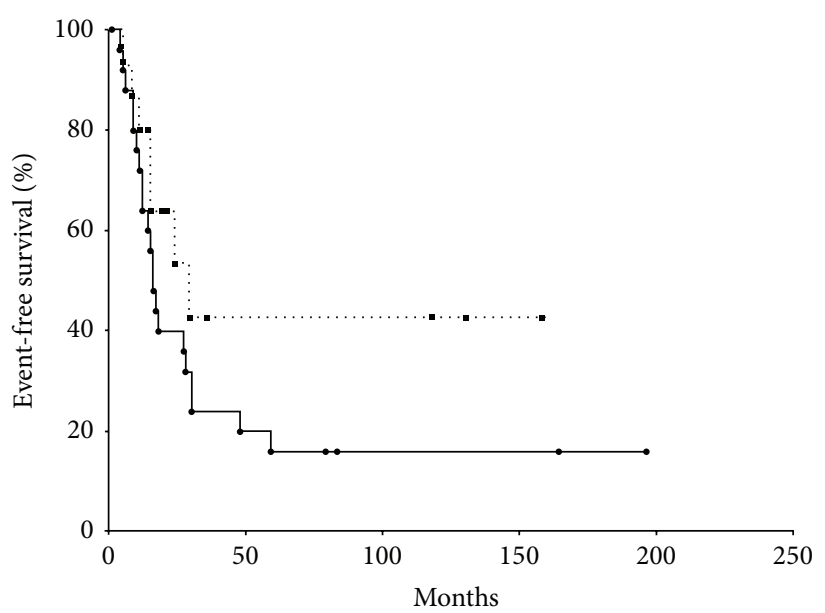

ARG-1 plasma levels

- Below median

..... Above median

(c)

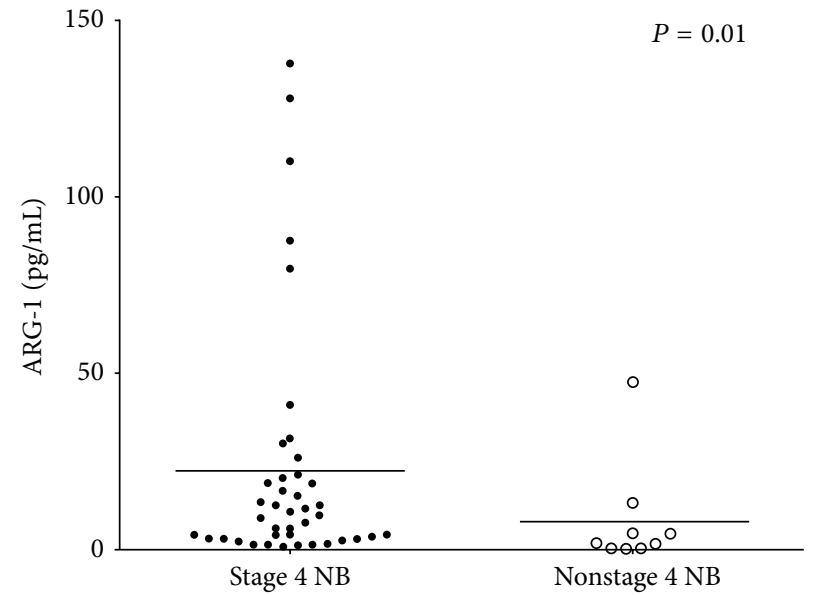

(b)

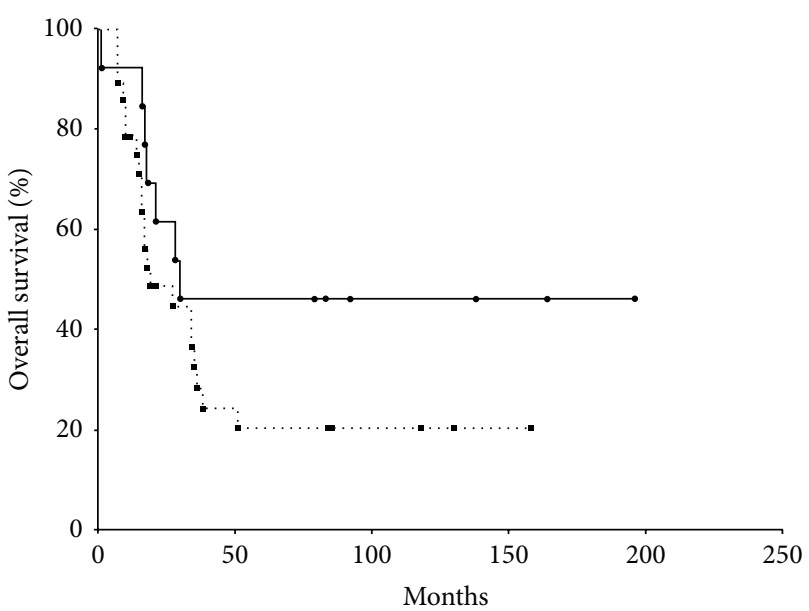

ARG-1 plasma levels
- Below median
..... Above median

(d)

FIGURE 4: ARG-1 plasma concentration in 57 NB patients and 30 healthy children (a, b), and association between ARG-1 plasma levels of stage 4 patients with EFS and OS (c, d). In (a), all NB patients and controls are shown. In (b), NB patients are stratified in stage $4\left(n^{\circ}=49\right)$ and non-stage $4\left(n^{\circ}=8\right)$. Results are expressed as $\mathrm{pg} / \mathrm{mL}$. Horizontal bars indicated means. $P$ values are indicated where differences are significant. Kaplan-Meyer plot of EFS (c) and OS (d) obtained by stratifying the 49 stage 4 NB patients according to ARG-1 plasma levels above (dotted line) or below (continuous line) median value. $Y$-axes represent $\%$ of event-free or alive patients, respectively. $X$-axes represent time of survival (months).

found in metastatic NB patients is in accordance with the finding reported by Tilak et al. [36] in human NB and with Treg involvement demonstrated in murine NB models [3740]. However, a direct relationship between the expansion of Treg cells in the PB and the increased levels of IL-10 in sera from NB patients could not be demonstrated. From our findings, also Trl cells did not appear to be responsible for the increased IL-10 plasma concentration. The present study is the first reporting on circulating Trl cells in NB patients. Thus, in view of the limited number of cases available for Tr1 analysis, further studies on larger cohorts are needed to confirm the reduction of Trl cells in metastatic NB. Moreover, this finding is in contrast with studies in head and neck tumors, where increased Tr1 cells were reported $[41,42]$.
It is of note that, in addition to the cell populations studied here, also NK, dendritic, and B cells can produce IL-10 [26]. Moreover, since IL-10R blockade prolonged survival in a murine NB model [43], we cannot exclude that inhibition of IL-10 levels may improve the clinical outcome of metastatic NB patients. Finally, the inverse correlation between FOXP3 and $I L-10$ expression in $\mathrm{PB}$ could be related to the fact that FOXP3 is not a Treg cell-specific marker but is also associated with $\mathrm{T}$ cell activation $[44,45]$.

Our study also showed that CD163 and $A R G-1$ mRNA expression were significantly higher in metastatic NB patients and significantly correlated with each other, suggesting that ARG-1 was expressed by myeloid cells. In different human tumors, ARG-1 was found overexpressed [46-48] and 


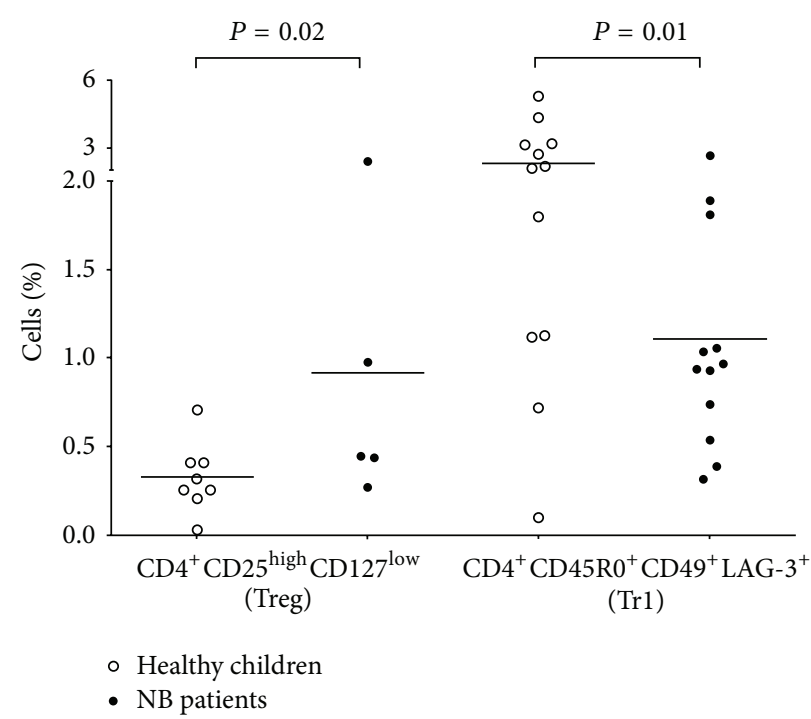

Figure 5: Percentages of Treg and Trl cells in PB samples from healthy children (empty circles) and children with metastatic NB (black circles). Data are expressed as \% of total cells. Horizontal bars indicated means. $P$ values are indicated where differences are significant.

responsible for immune suppression of antitumor responses [49-51]. Surprisingly, ARG-1 protein plasma levels in metastatic NB patients $>18$ months at diagnosis were lower than in healthy children. This contradictory finding may possibly relate to increased $A R G-1$ gene expression in MDSC and/or granulocytes, in the presence of reduced ARG-1 protein release. Indeed, ARG-1 is released by granulocytes during their degranulation in response to different stimuli. This finding may also be explained as a mechanism developed by NB cells to avoid arginine depletion caused by ARG-1 activity. Indeed, in tumors auxotrophic for arginine, tumor cell growth is hampered by arginine starvation. This mechanism was demonstrated in other human tumors, including melanoma [52-54], that share the same neural crest origin as NB. However, ARG-1 plasma concentration, as well as $A R G-1$ mRNA expression, did not significantly associate with survival, in patients with metastatic NB older than 18 months. In view of the opposite behavior of ARG-1 mRNA and protein, further studies are needed to exclude a possible role in metastatic NB.

\section{Conclusions}

Our data exclude a prognostic role of IL-10 and ARG-1 in metastatic NB and show that in human NB circulating Trl cells are decreased, whereas Treg cells are significantly increased. These data suggest the existence of a complex network of immune regulatory interactions involving IL10 and Treg cells, whose role in immune escape of NB should be further addressed. Combining agents targeting Treg inhibitory functions with immune enhancing agents may represent an interesting approach for therapeutic interventions.

\section{Conflict of Interests}

The authors declare that there is no conflict of interests regarding the publication of this paper.

\section{Authors' Contribution}

Fabio Morandi and Michela Croce equally contributed to the work. Silvano Ferrini and Maria Valeria Corrias equally contributed to the work.

\section{Acknowledgments}

This study was supported by Fondazione Italiana per la Lotta al Neuroblastoma (to Maria Valeria Corrias and Michela Croce), by AIRC IG13518 (to Silvano Ferrini), and by Ministero Della Salute (Ricerca Corrente and Cinque per mille to Vito Pistoia and Silvano Ferrini). Michela Croce is a recipient of Fondazione Italiana per la Lotta al Neuroblastoma fellowship. Secretarial assistance by Mrs. Camilla Valentino is deeply acknowledged.

\section{References}

[1] M. Kroesen, D. Lindau, P. Hoogerbrugge, and G. J. Adema, "Immunocombination therapy for high-risk neuroblastoma.," Immunotherapy, vol. 4, no. 2, pp. 163-174, 2012.

[2] J. M. Maris, "Recent advances in neuroblastoma," The New England Journal of Medicine, vol. 362, no. 23, pp. 2154-2211, 2010.

[3] G. M. Brodeur, J. Pritchard, F. Berthold et al., "Revisions of the international criteria for neuroblastoma diagnosis, staging, and response to treatment," Journal of Clinical Oncology, vol. 11, no. 8, pp. 1466-1477, 1993. 
[4] S. L. Cohn, A. D. J. Pearson, W. B. London et al., "The International Neuroblastoma Risk Group (INRG) classification system: an INRG task force report," Journal of Clinical Oncology, vol. 27, no. 2, pp. 289-297, 2009.

[5] S. Shusterman, W. B. London, S. D. Gillies et al., "Antitumor activity of Hu14.18-IL2 in patients with relapsed/refractory neuroblastoma: a Children's Oncology Group (COG) phase II study," Journal of Clinical Oncology, vol. 28, no. 33, pp. 49694975, 2010.

[6] R. Ladenstein, S. Weixler, B. Baykan et al., "Ch14.18 antibody produced in $\mathrm{CHO}$ cells in relapsed or refractory stage 4 neuroblastoma patients: a SIOPEN phase 1 study," $m A b s$, vol. 5 , no. 5, pp. 801-809, 2013.

[7] M. V. Corrias, M. Occhino, M. Croce et al., "Lack of HLAclass I antigens in human neuroblastoma cells: analysis of its relationship to TAP and tapasin expression," Tissue Antigens, vol. 57, no. 2, pp. 110-117, 2001.

[8] R. Castriconi, A. Dondero, R. Augugliaro et al., "Identification of 4Ig-B7-H3 as a neuroblastoma-associated molecule that exerts a protective role from an NK cell-mediated lysis," Proceedings of the National Academy of Sciences of the United States of America, vol. 101, no. 34, pp. 12640-12645, 2004.

[9] R. Castriconi, A. Dondero, F. Bellora et al., "Neuroblastomaderived IL- $\beta 1$ modulates the chemokine receptor repertoire of human resting nk cells," Journal of Immunology, vol. 190, no. 10, pp. 5321-5328, 2013.

[10] F. Morandi, G. Cangemi, S. Barco et al., "Plasma levels of soluble HLA-E and HLA-F at diagnosis may predict overall survival of neuroblastoma patients," BioMed Research International, vol. 2013, Article ID 956878, 9 pages, 2013.

[11] F. Morandi, P. Scaruff, F. Gallo et al., "Bone marrow-infiltrating human neuroblastoma cells express high levels of calprotectin and HLA-g proteins," PLoS ONE, vol. 7, no. 1, Article ID e29922, 2012.

[12] F. Morandi, M. V. Corrias, I. Levreri et al., "Serum levels of cytoplasmic melanoma-associated antigen at diagnosis may predict clinical relapse in neuroblastoma patients," Cancer Immunology, Immunotherapy, vol. 60, no. 10, pp. 1485-1495, 2011.

[13] F. Morandi, I. Levreri, P. Bocca et al., "Human neuroblastoma cells trigger an immunosuppressive program in monocytes by stimulating soluble HLA-G release," Cancer Research, vol. 67, no. 13, pp. 6433-6441, 2007.

[14] A. L. Yu, A. L. Gilman, M. F. Ozkaynak et al., "Anti-GD2 antibody with GM-CSF, interleukin-2, and isotretinoin for neuroblastoma," New England Journal of Medicine, vol. 363, no. 14, pp. 1324-1334, 2010.

[15] R. C. Seeger, "Immunology and immunotherapy of neuroblastoma," Seminars in Cancer Biology, vol. 21, no. 4, pp. 229-237, 2011.

[16] S. Asgharzadeh, R. Pique-Regi, R. Sposto et al., "Prognostic significance of gene expression profiles of metastatic neuroblastomas lacking MYCN gene amplification," Journal of the National Cancer Institute, vol. 98, no. 17, pp. 1193-1203, 2006.

[17] S. Asgharzadeh, J. A. Salo, L. Ji et al., "Clinical significance of tumor-associated inflammatory cells in metastatic neuroblastoma," Journal of Clinical Oncology, vol. 30, no. 28, pp. 35253532, 2012.

[18] L. Song, S. Asgharzadeh, J. Salo et al., "V $\alpha 24$-invariant NKT cells mediate antitumor activity via killing of tumor-associated macrophages," Journal of Clinical Investigation, vol. 119, no. 6 , pp. 1524-1536, 2009.
[19] X. Cao, "Regulatory T cells and immune tolerance to tumors," Immunologic Research, vol. 46, no. 1-3, pp. 79-93, 2010.

[20] M. Gowda, K. Godder, M. Kmieciak et al., "Distinct signatures of the immune responses in low risk versus high risk neuroblastoma," Journal of Translational Medicine, vol. 9, article 170, 2011.

[21] H. Groux, A. O’Garra, M. Bigler et al., "A CD4 ${ }^{+}$T-cell subset inhibits antigen-specific T-cell responses and prevents colitis," Nature, vol. 389, no. 6652, pp. 737-742, 1997.

[22] M. Battaglia, S. Gregori, R. Bacchetta, and M.-G. Roncarolo, "Tr1 cells: from discovery to their clinical application," Seminars in Immunology, vol. 18, no. 2, pp. 120-127, 2006.

[23] S. Gregori, K. S. Goudy, and M. G. Roncarolo, "The cellular and molecular mechanisms of immuno-suppression by human type 1 regulatory T cells," Frontiers in Immunology, vol. 3, article 30, 2012.

[24] M. G. Roncarolo, S. Gregori, M. Battaglia, R. Bacchetta, K. Fleischhauer, and M. K. Levings, "Interleukin-10-secreting type 1 regulatory $\mathrm{T}$ cells in rodents and humans," Immunological Reviews, vol. 212, no. 1, pp. 28-50, 2006.

[25] N. Gagliani, C. F. Magnani, S. Huber et al., "Coexpression of $\mathrm{CD} 49 \mathrm{~b}$ and LAG-3 identifies human and mouse T regulatory type 1 cells," Nature Medicine, vol. 19, no. 6, pp. 739-746, 2013.

[26] M. Saraiva and A. O'Garra, "The regulation of IL-10 production by immune cells," Nature Reviews Immunology, vol. 10, no. 3, pp. 170-181, 2010.

[27] R. Haupt, A. Garaventa, C. Gambini et al., "Improved survival of children with neuroblastoma between 1979 and 2005: a report of the Italian neuroblastoma registry," Journal of Clinical Oncology, vol. 28, no. 14, pp. 2331-2338, 2010.

[28] P. Scaruffi, S. Stigliani, S. Moretti et al., "Transcribed-ultra conserved region expression is associated with outcome in high-risk neuroblastoma," BMC Cancer, vol. 9, article 441, 2009.

[29] V. F. Viprey, M. V. Corrias, B. Kagedal et al., "Standardisation of operating procedures for the detection of minimal disease by QRT-PCR in children with neuroblastoma: quality assurance on behalf of SIOPEN-R-NET," European Journal of Cancer, vol. 43, no. 2, pp. 341-350, 2007.

[30] K. J. Livak and T. D. Schmittgen, "Analysis of relative gene expression data using real-time quantitative PCR and the $2^{-\Delta \Delta \mathrm{CT}}$ method," Methods, vol. 25, no. 4, pp. 402-408, 2001.

[31] T. L. Whiteside, "Regulatory T cell subsets in human cancer: are they regulating for or against tumor progression?" Cancer Immunology, Immunotherapy, vol. 63, no. 1, pp. 67-72, 2014.

[32] S. Reinartz, T. Schumann, F. Finkernagel et al., "Mixedpolarization phenotype of ascites-associated macrophages in human ovarian carcinoma: correlation of CD163 expression, cytokine levels and early relapse," International Journal of Cancer, vol. 134, no. 1, pp. 32-42, 2014.

[33] S. Wang, M. Sun, C. Gu et al., "Expression of CD163, interleukin-10, and interferon-gamma in oral squamous cell carcinoma: mutual relationships and prognostic implications," European Journal of Oral Sciences, vol. 122, no. 3, pp. 202-209, 2014.

[34] M. Prosniak, L. A. Harshyne, D. W. Andrews et al., "Glioma grade is associated with the accumulation and activity of cells bearing M2 monocyte markers," Clinical Cancer Research, vol. 19, no. 14, pp. 3776-3786, 2013.

[35] K. Fujio, T. Okamura, and K. Yamamoto, "The family of IL-10secreting CD $4^{+} \mathrm{T}$ cells," Advances in Immunology, vol. 105, pp. 99-130, 2010. 
[36] T. Tilak, S. Sherawat, S. Agarwala, R. Gupta, S. Vishnubhatla, and S. Bakhshi, "Circulating T-regulatory cells in neuroblastoma: a pilot prospective study," Pediatric HematologyOncology, 2014.

[37] V. Rigo, M. V. Corrias, A. M. Orengo et al., "Recombinant IL-21 and anti-CD4 antibodies cooperate in syngeneic neuroblastoma immunotherapy and mediate long-lasting immunity," Cancer Immunology, Immunotherapy, vol. 63, no. 5, pp. 501-511, 2014.

[38] W. Jing, X. Yan, W. H. D. Hallett, J. A. Gershan, and B. D. Johnson, "Depletion of $\mathrm{CD}_{2} 5^{+} \mathrm{T}$ cells from hematopoietic stem cell grafts increases posttransplantation vaccine-induced immunity to neuroblastoma," Blood, vol. 117, no. 25, pp. $6952-$ 6962, 2011.

[39] W. Jing, J. A. Gershan, and B. D. Johnson, "Depletion of CD4 T cells enhances immunotherapy for neuroblastoma after syngeneic HSCT but compromises development of antitumor immune memory," Blood, vol. 113, no. 18, pp. 4449-4457, 2009.

[40] M. Croce, M. V. Corrias, A. M. Orengo et al., "Transient depletion of $\mathrm{CD}^{+} \mathrm{T}$ cells augments IL-21-based immunotherapy of disseminated neuroblastoma in syngeneic mice," International Journal of Cancer, vol. 127, no. 5, pp. 1141-1150, 2010.

[41] C. Bergmann, L. Strauss, R. Zeidler, S. Lang, and T. L. Whiteside, "Expansion of human T regulatory type 1 cells in the microenvironment of cyclooxygenase 2 overexpressing head and neck squamous cell carcinoma," Cancer Research, vol. 67, no. 18, pp. 8865-8873, 2007.

[42] C. Bergmann, L. Strauss, Y. Wang et al., “T regulatory type 1 cells in squamous cell carcinoma of the head and neck: mechanisms of suppression and expansion in advanced disease," Clinical Cancer Research, vol. 14, no. 12, pp. 3706-3715, 2008.

[43] C. Brignole, D. Marimpietri, F. Pastorino et al., "Anti-IL10R antibody improves the therapeutic efficacy of targeted liposomal oligonucleotides," Journal of Controlled Release, vol. 138, no. 2, pp. 122-127, 2009.

[44] R. J. deLeeuw, S. E. Kost, J. A. Kakal, and B. H. Nelson, "The prognostic value of FoxP3+ tumor-infiltrating lymphocytes in cancer: a critical review of the literature," Clinical Cancer Research, vol. 18, no. 11, pp. 3022-3029, 2012.

[45] F. Martin, S. Ladoire, G. Mignot, L. Apetoh, and F. Ghiringhelli, "Human FOXP3 and cancer," Oncogene, vol. 29, no. 29, pp. 41214129, 2010.

[46] F. Mussai, C. de Santo, I. Abu-Dayyeh et al., "Acute myeloid leukemia creates an arginase-dependent immunosuppressive microenvironment," Blood, vol. 122, no. 5, pp. 749-758, 2013.

[47] P. C. Rodriguez, M. S. Ernstoff, C. Hernandez et al., "Arginase I-producing myeloid-derived suppressor cells in renal cell carcinoma are a subpopulation of activated granulocytes," Cancer Research, vol. 69, no. 4, pp. 1553-1560, 2009.

[48] R. Rotondo, G. Barisione, L. Mastracci et al., "IL-8 induces exocytosis of arginase 1 by neutrophil polymorphonuclears in nonsmall cell lung cancer," International Journal of Cancer, vol. 125, no. 4, pp. 887-893, 2009.

[49] P. C. Rodriguez, D. G. Quiceno, J. Zabaleta et al., "Arginase I production in the tumor microenvironment by mature myeloid cells inhibits T-cell receptor expression and antigen-specific Tcell responses," Cancer Research, vol. 64, no. 16, pp. 5839-5849, 2004.

[50] V. Bronte and P. Zanovello, "Regulation of immune responses by L-arginine metabolism," Nature Reviews Immunology, vol. 5, no. 8, pp. 641-654, 2005.

[51] C. de Santo, P. Serafini, I. Marigo et al., "Nitroaspirin corrects immune dysfunction in tumor-bearing hosts and promotes tumor eradication by cancer vaccination," Proceedings of the National Academy of Sciences of the United States of America, vol. 102, no. 11, pp. 4185-4190, 2005.

[52] P. N.-M. Cheng, T.-L. Lam, W.-M. Lam et al., "Pegylated recombinant human arginase (rhArg-peg5,000 mw) inhibits the in vitro and in vivo proliferation of human hepatocellular carcinoma through arginine depletion," Cancer Research, vol. 67, no. 1, pp. 309-317, 2007.

[53] E. S. Glazer, E. M. Stone, C. Zhu, K. L. Massey, A. N. Hamir, and S. A. Curley, "Bioengineered human arginase I with enhanced activity and stability controls hepatocellular and pancreatic carcinoma xenografts," Translational Oncology, vol. 4, no. 3, pp. 138-146, 2011.

[54] M. T. Kuo, N. Savaraj, and L. G. Feun, "Targeted cellular metabolism for cancer chemotherapy with recombinant arginine-degrading enzymes.," Oncotarget, vol. 1, no. 4, pp. 246251, 2010. 


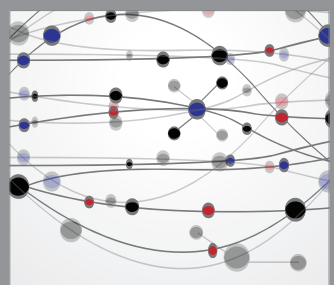

The Scientific World Journal
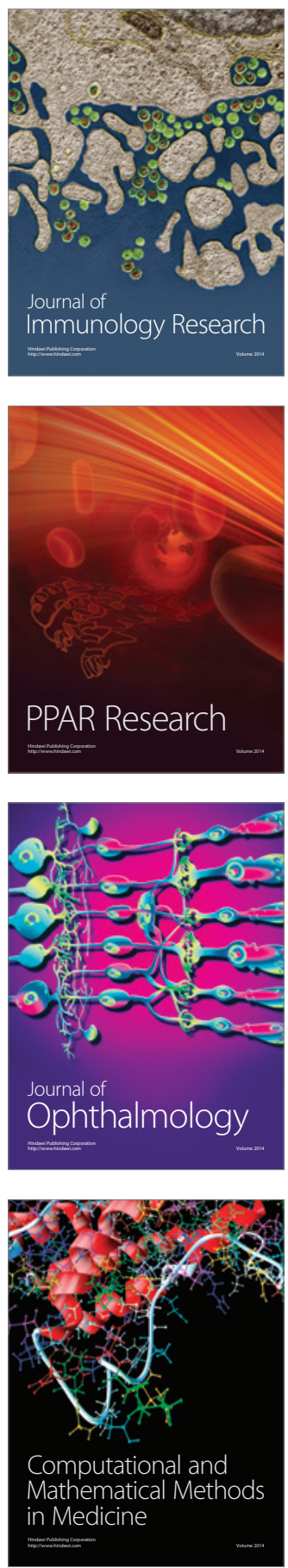

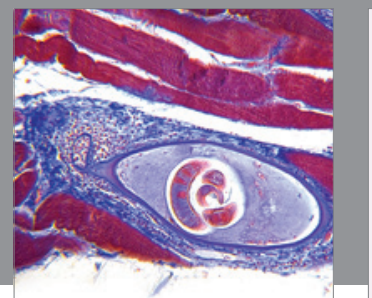

Gastroenterology

Research and Practice
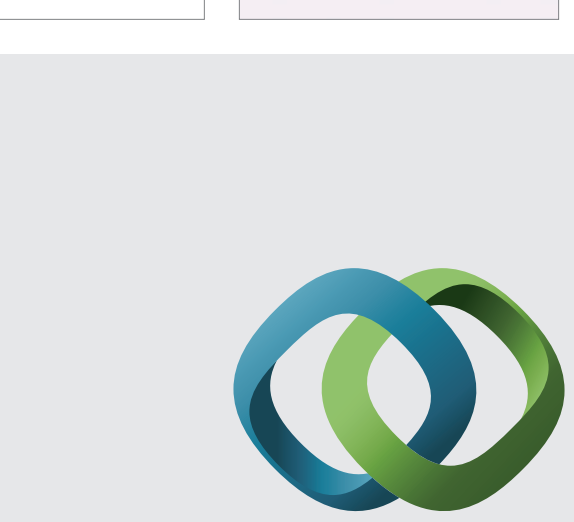

\section{Hindawi}

Submit your manuscripts at

http://www.hindawi.com
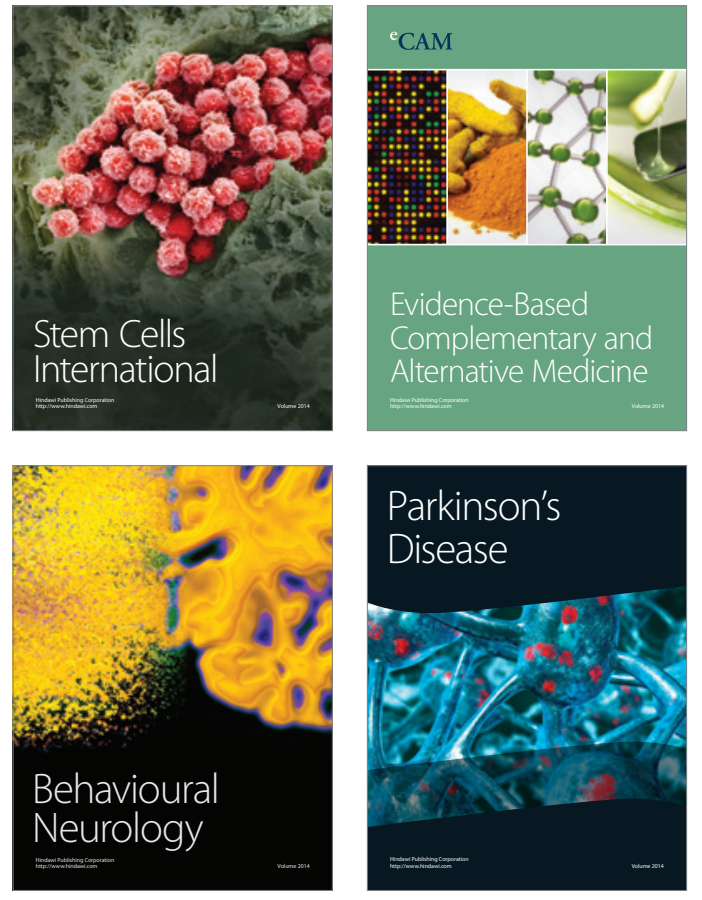
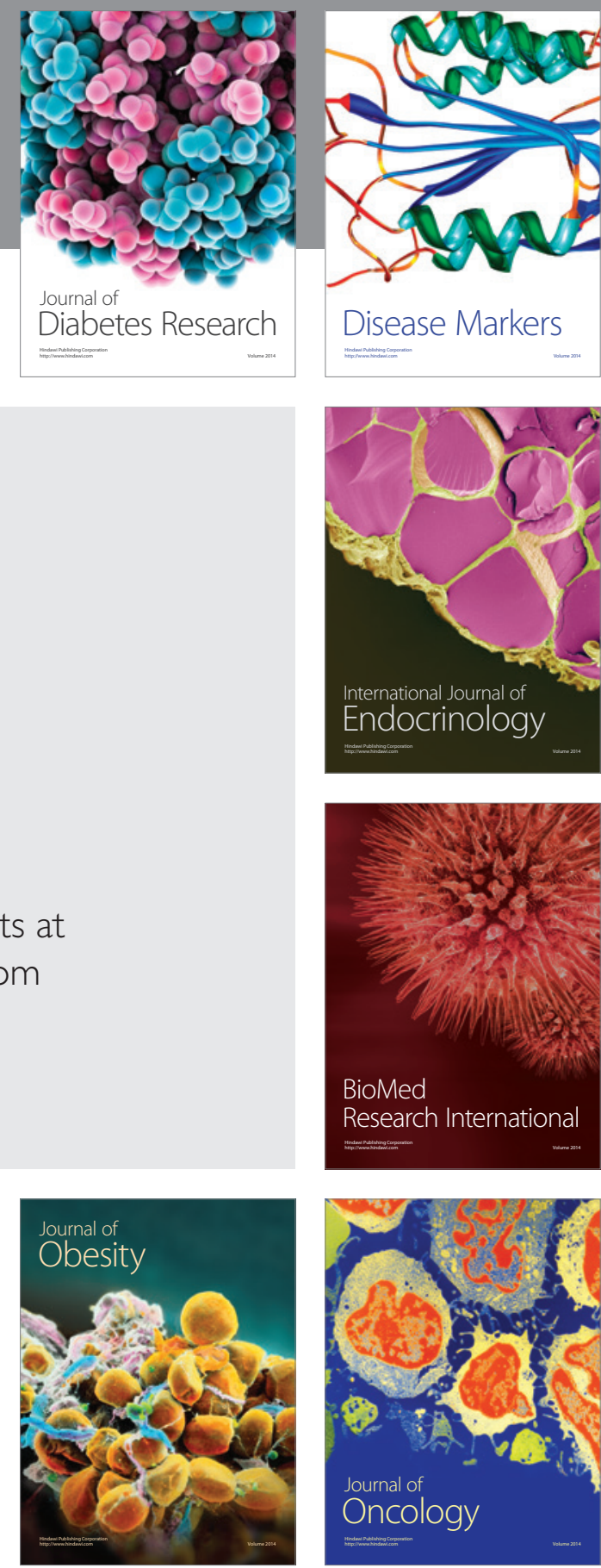

Disease Markers
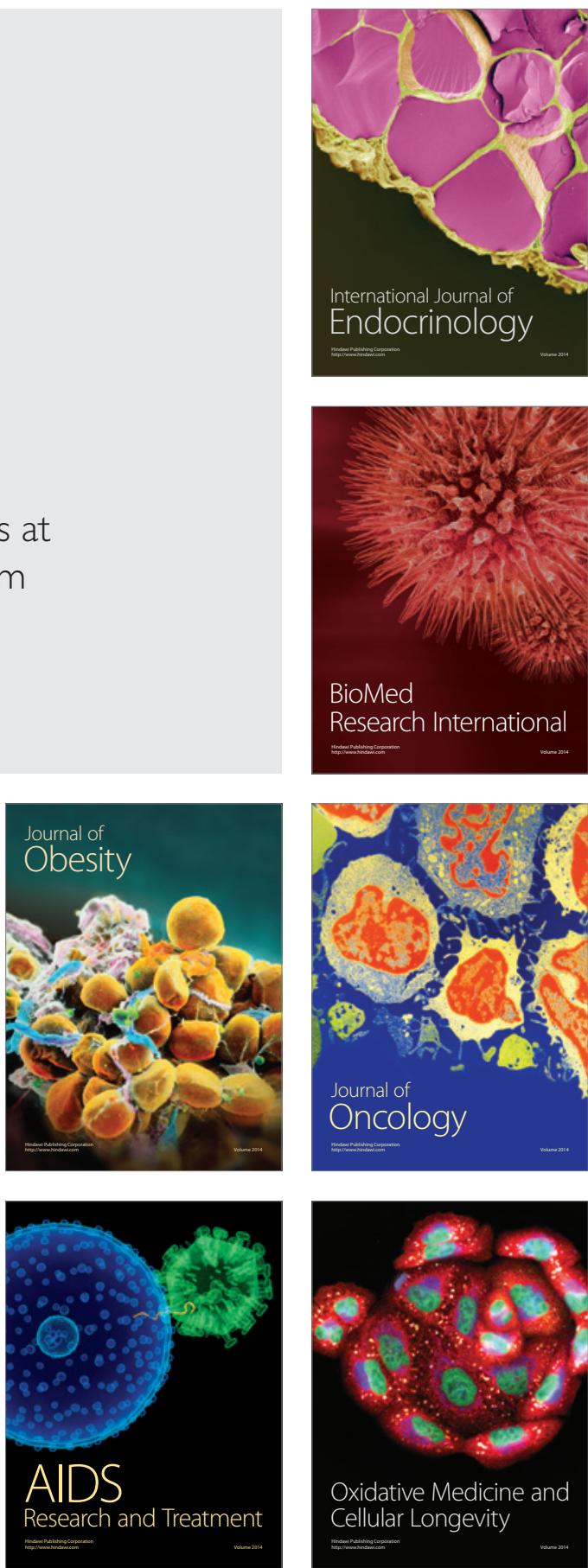